\title{
Radiology Reporting Errors: Learning from Report Addenda
}

\author{
Anurima Patra ${ }^{1}$ Manthreshwar Premkumar ${ }^{1}$ Shyamkumar N. Keshava ${ }^{1}$ Anuradha Chandramohan ${ }^{1}$ \\ Elizabeth Joseph ${ }^{1}$ Sridhar Gibikote ${ }^{1}$
}

${ }^{1}$ Department of Radiology, Christian Medical College, Vellore, Tamil Nadu, India

Indian J Radiol Imaging 2021;31:333-344.
Address for correspondence Sridhar Gibikote, Department of Radiology, Christian Medical College, Vellore 632 004, Tamil Nadu, India (e-mail: gibikote@cmcvellore.ac.in).

\begin{abstract}
Keywords

- addenda

- diagnostic error rate

- misinterpretation

- radiological discrepancy

Background The addition of new information to a completed radiology report in the form of an "addendum" conveys a variety of information, ranging from less significant typographical errors to serious omissions and misinterpretations. Understanding the reasons for errors and their clinical implications will lead to better clinical governance and radiology practice.

Aims This article assesses the common reasons which lead to addenda generation to completed reports and their clinical implications.

Subjects and Methods Retrospective study was conducted by reviewing addenda to computed tomography (CT), ultrasound, and magnetic resonance imaging reports between January 2018 to June 2018 , to note the frequency and classification of report addenda.

Results Rate of addenda generation was $1.1 \%(n=1,076)$ among the 97,003 approved cross-sectional radiology reports. Errors contributed to $71.2 \%(n=767)$ of addenda, most commonly communication $(29.3 \%, n=316)$ and observational errors $(20.8 \%$, $n=224$ ), and $28.7 \%$ were nonerrors aimed at providing additional clinically relevant information. Majority of the addenda $(82.3 \%, n=886)$ did not have a significant clinical impact. CT and ultrasound reports accounted for $36.9 \%(n=398)$ and $35.2 \%(n$ $=379)$ share, respectively. A time gap of 1 to 7 days was noted for $46.8 \%(n=504)$ addenda and $37.6 \%(n=405)$ were issued in less than a day. Radiologists with more than 6 -year experience created majority $(1.5 \%, n=456)$ of addenda. Those which were added to reports generated during emergency hours contributed to $23.2 \%(n=250)$ of the addenda.

Conclusion The study has identified the prevalence of report addenda in a radiology practice involving picture archiving and communication system in a tertiary care center in India. The etiology included both errors and non-errors. Results of this audit were used to generate a checklist and put protocols that will help decrease serious radiology misses and common errors.
\end{abstract}

published online August 12, 2021
DOI https://doi.org/ $10.1055 / \mathrm{s}-0041-1734351$ ISSN 0971-3026 (c) 2021. Indian Radiological Association.

This is an open access article published by Thieme under the terms of the Creative Commons Attribution-NonDerivative-NonCommercial-License, permitting copying and reproduction so long as the original work is given appropriate credit. Contents may not be used for commercial purposes, or adapted, remixed, transformed or built upon. (https://creativecommons.org/licenses/by-nc-nd/4.0/). Thieme Medical and Scientific Publishers Private Ltd. A-12, Second Floor, Sector -2, NOIDA -201301, India 


\section{Introduction}

Sometimes radiologists approve the report only to realize later that certain additional information had to be mentioned in the report. Or, the radiologist's opinion may change when other clinical data are available at a later time. In such situations, where there is a need to add new comments or clarification to the original report, software tools such as "report addenda" can prove to be very useful. This has been possible because of the worldwide availability of picture archiving and communication system (PACS) in the last few decades, which has revolutionized the radiological documentation, making the reports electronically and promptly available to the referring clinicians and patients.

\section{What is a Report Addendum?}

An "addendum" is the supplementary text added at the end of a previously approved radiology report, to correct or expand on an original statement ( $\mathbf{- F i g . ~ 1 ) . ~}{ }^{1}$ It is not just "discrepancy documentation," but can become the most crucial part of the report, not only for medical and ethical implications, but also for medicolegal consequences. ${ }^{2}$

The new information conveyed ranges from less significant typographical errors to serious clinically significant misses. ${ }^{3}$ The addendum and the original report, are available for viewing together, hence eliminating the need for deletion of the original report by the radiologist at a later date. It also contains a record of the date, and reason for the addition or clarification of information being added to the medical history.

In this study, we aim to study the frequency and common causes for addenda generation in radiology reports in our institution with everyday scenarios and examples. We also discuss possible solutions to minimize errors.

\section{Subjects and Methods}

\section{Study Group}

This retrospective study was performed in a tertiary care hospital in India, after approval by the institutional review board (IRB No: 11744/2018). All the approved cross-sectional radiology reports generated over 6 months between January 2018 and June 2018 were searched from the radiology information system (RIS). - Fig. 2 shows the flowchart of the included patients.

\section{Report and Image Analysis}

All the original reports, addenda, and images were reviewed by two radiologists and categorized as below. Patient records were also examined to determine the effect of the initial report on management and clinical outcome.

\section{Imaging modalities:}

Finalized computed tomography (CT), magnetic resonance imaging (MRI), and ultrasound reports were included for the study.

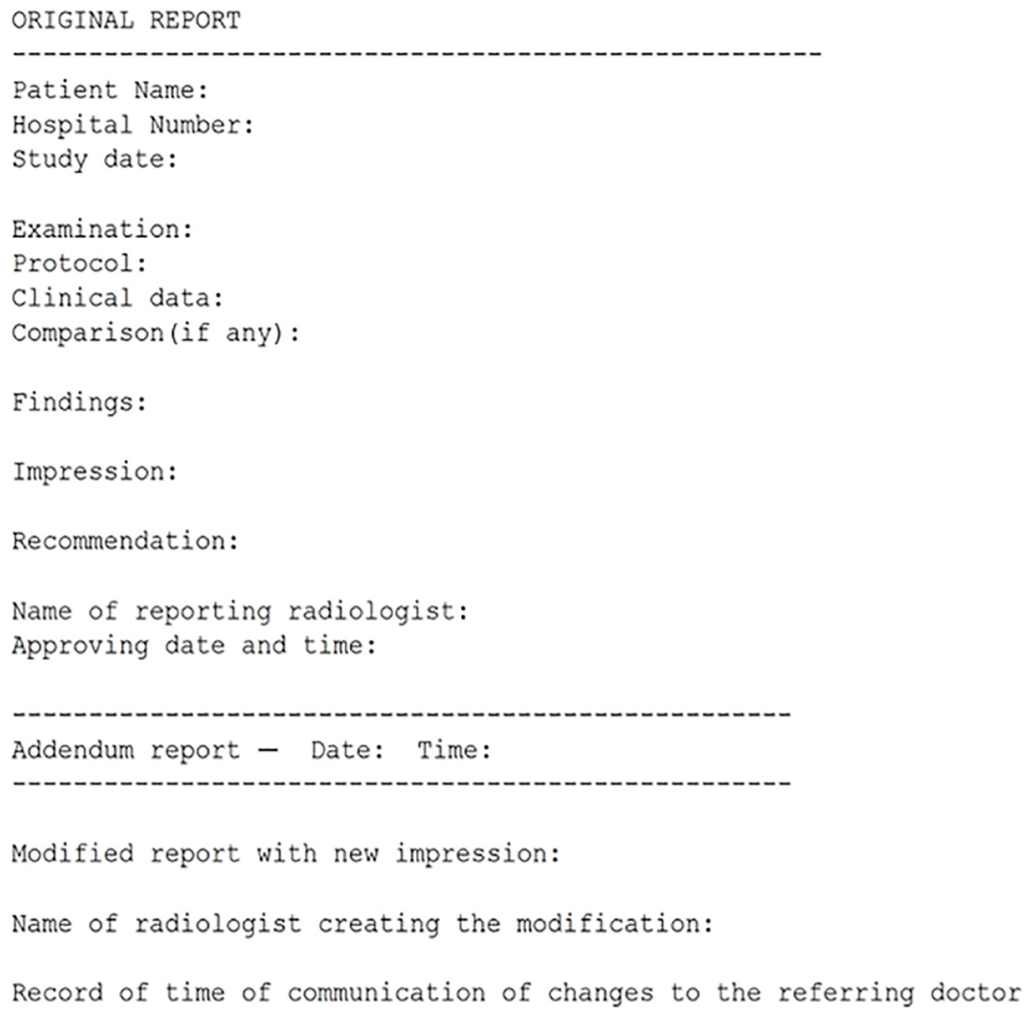

Fig. 1 Report template. The addenda is added at the end of the initial report. The entire report should be rewritten in the addenda and not just the modified portions. Both reports should be available for viewing together. 


\section{Total approved radiology reports over 6- month duration $(n=108995)$}

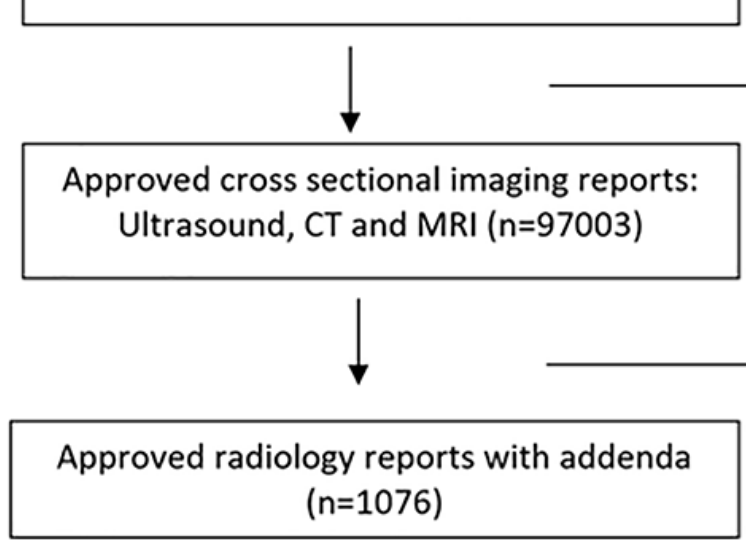

Fig. 2 Schematic representation of the selection of study population.

2. Time of generation and time delay:

The time delay between the original report and addenda was calculated based on the time of generation already recorded in the addenda and divided as less than one day, 1 to 7 days, 8 to 30 days, and more than 30 days. Addenda were also classified based on whether they were generated during regular work hours or emergency hours.

\section{Etiology:}

We classified addenda into 10 broad categories and subcategories based on the reasons for creation ( - Table 1). They were also divided into "error" and "non-error" addenda (-Fig. 12).

\section{Clinical significance:}

The medical charts of all patients were reviewed and the clinical importance of modification in report content was graded into five categories (- Table 2). ${ }^{4}$ Clinically significant addenda were those who had the potential to change the diagnosis and immediate patient management, and affect patient morbidity. Nonsignificant clinical addenda were related to patient demography, spelling errors, records of communication, etc.

\section{Experience:}

We classified the residents and consultants based on their expertise in radiology into three groups: junior residents ( $<4$ years' experience), junior consultants and fellows with 4 to 6 years' experience, and assistant/associate professors or higher ranks, including specialist radiologists ( $>6$ years' experience).

\section{Results}

Addenda rate: In the 6 months study period, out of a total of 97,003 approved cross-sectional radiology reports, addenda was generated in 1,076 reports, yielding an overall frequency of $1.1 \%$. Twenty-three reports had more than one addenda added to the same report. Ninety-six percent of addenda were created by the author of the original report.

\section{Classification Based on Etiology}

Errors contributed to a $71.2 \%(n=767 / 1,076)$ share of addenda or $0.8 \%(767 / 97,003)$ of total approved reports. Communication errors were most common $(29.3 \%, n=316)$ followed by observational errors $(20.8 \%, n=224)$ and interpretation errors $(17.7 \%, n=191)$. Among the subtypes, the most common were errors due to typographical reasons ( $n$ $=136$ ), followed by an incomplete description of the findings ( $n=110)$ and under reading $(n=118)$. - Table 3 shows the percentage of each reason for addenda creation.

Non-error addenda contributed to $28.7 \%$ ( $n=309 / 1,076$ ) reports, out of which 50.1\% ( $n=155 / 309)$ contribution was by "limitations of modality." This group included reports, in which definite diagnosis could not be made on one particular imaging modality or sequence, and patients were called back for additional imaging. The conclusion was added to the original report as addenda.

\section{Classification Based on Imaging Modalities}

Among the imaging modalities, 36.9\% $(n=398)$ of the addenda were added to CT reports, followed by $35.2 \%$ $(n=379)$ in ultrasound reports and $27.7 \%(n=299)$ in MRI reports.

\section{Time Interval}

The range of time interval between the sign-off of the original reports and addition of addenda was 0 to 273 days, with an average of 2 days. Majority of addenda were issued in 1 to 7 days $(46.8 \%, n=504)$ while $37.6 \%(n=405)$ were issued in less than 24 hours ( - Fig. 13). Higher time gaps of more than a month $(n=7 / 1,076)$, were due to the addition of comparison 
Table 1 Categories of report addenda based on the reasons for creation

\begin{tabular}{|c|c|c|}
\hline Cause of error & Explanation & Example \\
\hline \multicolumn{3}{|l|}{ 1. Observational error } \\
\hline Under reading & $\begin{array}{l}\text { Additional abnormalities missed after one finding detected, } \\
\text { possibly due to the satisfaction of search or work fatigue or } \\
\text { distractions. ( - Fig. 3) }\end{array}$ & $\begin{array}{l}\text { Missing splenic abscess after appendicitis is } \\
\text { diagnosed }\end{array}$ \\
\hline $\begin{array}{l}\text { All images not read/ } \\
\text { reported }\end{array}$ & Finding missed because all images in the study were not read & \\
\hline Location & $\begin{array}{l}\text { Finding missed because of location outside the area of clinical } \\
\text { interest or in the last sections of images ( }- \text { Fig. } 4 \text { and } 5 \text { ) }\end{array}$ & $\begin{array}{l}\text { Missing pulmonary embolism in CT abdomen } \\
\text { as lower sections of thorax not checked. }\end{array}$ \\
\hline Prior examination & $\begin{array}{l}\text { Finding missed due to overreliance on previous reports without } \\
\text { seeing images, or not checking previous reports and images. }\end{array}$ & \\
\hline \multicolumn{3}{|l|}{ 2. Interpretation error } \\
\hline Faulty reasoning & $\begin{array}{l}\text { Finding appreciated but misinterpreted, possibly due to lack } \\
\text { of knowledge, limitations of imaging modality or insufficient } \\
\text { clinical data. }\end{array}$ & \\
\hline Faulty reasoning & $\begin{array}{l}\text { More differentials added, as findings not fitting to one diagnosis. } \\
\text { Negative points ruling out alternative diagnosis missed }\end{array}$ & $\begin{array}{l}\text { Multiple differentials for pancreatic lesions } \\
\text { added due to atypical imaging features }\end{array}$ \\
\hline Incomplete description & $\begin{array}{l}\text {-Finding appreciated and mentioned in the report but not suffi- } \\
\text { ciently elaborated or summarized. } \\
\text {-Negative points ruling out alternative diagnosis missed. }\end{array}$ & $\begin{array}{l}\text { Size or extent of disease for malignancy. } \\
\text { The volume of urinary bladder clot. }\end{array}$ \\
\hline Over-reporting & Normal reported as abnormal (false-positive error). ( - Fig. 6) & $\begin{array}{l}\text { Collapsed bowel misinterpreted as bowel wall } \\
\text { thickening. }\end{array}$ \\
\hline \multicolumn{3}{|c|}{ 3. Transcription or communication error } \\
\hline $\begin{array}{l}\text { Physician } \\
\text { communication }\end{array}$ & $\begin{array}{l}\text {-Critical or unexpected findings not communicated to the } \\
\text { physician. } \\
\text {-Note added requesting the physician to discuss the case with } \\
\text { more clinical history. }\end{array}$ & \\
\hline $\begin{array}{l}\text { Further } \\
\text { recommendations }\end{array}$ & Failure to suggest the next step to guide the physician. & $\begin{array}{l}\text { Follow-up with specific imaging sequences, } \\
\text { lab tests etc }\end{array}$ \\
\hline Typographic error & Mismatch of gender, age, laterality and spelling errors. & \\
\hline $\begin{array}{l}\text { Erroneous report/ } \\
\text { template related errors }\end{array}$ & $\begin{array}{l}\text {-Report generated in error and belonging to another patient. } \\
\text {-Pasting common formats and not removing the non-applicable } \\
\text { points. } \\
\text {-Report approved by mistake. } \\
\text {-Wrong scan title or incorrect clinical data entered. } \\
\text {-Copy-paste error: details copied from the previous report, not } \\
\text { applicable to the present report. }\end{array}$ & $\begin{array}{l}\text {-Gallbladder reported as normal in a } \\
\text { post-cholecystectomy patient } \\
\text {-Mentioning prostate in females and uterus } \\
\text { in males }\end{array}$ \\
\hline Incomplete report & $\begin{array}{l}\text {-Findings picked up during the reading of scan but missed out on } \\
\text { mentioning in the body or impression } \\
\text {-Only abnormalities mentioned. Unremarkable structures not } \\
\text { added. }\end{array}$ & $\begin{array}{l}\text {-Name of reporting radiologist not added } \\
\text {-Findings in some organs left blank in the } \\
\text { template. }\end{array}$ \\
\hline \multicolumn{3}{|c|}{ 4. Additional remarks/ comments } \\
\hline & $\begin{array}{l}\text {-Not a report error, but a clarification of previously described } \\
\text { finding. } \\
\text {-Review and confirmation of the conclusions reported by another } \\
\text { radiologist }\end{array}$ & $\begin{array}{l}\text {-The volume of the liver before hepatectomy } \\
\text { added on clinician's request. } \\
\text {-Color of aspirated fluid added to the report } \\
\text { for a CT-guided aspiration procedure. }\end{array}$ \\
\hline \multicolumn{3}{|l|}{ 5. Clinical history } \\
\hline & $\begin{array}{l}\text {-Finding missed or misinterpreted because of inaccurate or } \\
\text { absent clinical history. } \\
\text {-Not paying attention to history. } \\
\text {-Overreliance on history ( - Fig. } \mathbf{7} \text { ). }\end{array}$ & \\
\hline \multicolumn{3}{|l|}{ 6. Study limitations } \\
\hline Limitations of modality & $\begin{array}{l}\text { Help of another modality sought to remove the ambiguity in } \\
\text { findings (- Fig. } 8 \text { ). }\end{array}$ & $\begin{array}{l}\text { Liver lesion detected on } \mathrm{CT} \text {, but additional } \\
\text { MRI done for characterization. }\end{array}$ \\
\hline $\begin{array}{l}\text { Limited sequences/ } \\
\text { views }\end{array}$ & $\begin{array}{l}\text { Views within the same modality too limited to give a definite } \\
\text { opinion. More sequences done as a problem-solving tool. }\end{array}$ & $\begin{array}{l}\text { Additional DRIVE sequence requested to } \\
\text { identify scolex in the brain ( }- \text { Fig. } 9 \text { ). }\end{array}$ \\
\hline
\end{tabular}


Table 1 Categories of report addenda based on the reasons for creation

\begin{tabular}{|l|l|l|}
\hline Cause of error & Explanation & \multicolumn{1}{|c|}{ Example } \\
\hline $\begin{array}{l}\text { Limitations of } \\
\text { technique/ protocol }\end{array}$ & $\begin{array}{l}\text { Finding misinterpreted due to scan-related factors such as con- } \\
\text { trast vs non-contrast, supine vs prone, incorrect scan parameters, } \\
\text { incorrect windowing, the plane of imaging, artefacts } \\
\text { (-Fig. 10 and 11). }\end{array}$ & $\begin{array}{l}\text { Inaccurate local staging of carcinoma rectum } \\
\text { due to wrong scanning planes. }\end{array}$ \\
\hline 7. Comparison & $\begin{array}{l}\text {-Forgot to compare disease status with an already available prior } \\
\text { imaging. } \\
\text {-Comparing with films of scan done elsewhere, made available at } \\
\text { a later date. }\end{array}$ & \\
\hline 8. Follow-up & \multicolumn{2}{|l|}{} \\
\hline & $\begin{array}{l}\text { Record of complications or follow-up of an intervention } \\
\text { procedure. }\end{array}$ & $\begin{array}{l}\text {-Resolution of a collection after pigtail } \\
\text { insertion. } \\
\text {-Resolution of intussusception after reduction }\end{array}$ \\
\hline 9. Patient-related limitations & $\begin{array}{l}\text {-Study incomplete or suboptimal due to patient-related factors. } \\
\text { Findings added as addenda at a later date/ time after completion. }\end{array}$ & $\begin{array}{l}\text {-Empty urinary bladder or bowel gas shadows } \\
\text { on Ultrasound. } \\
\text {-Movement artefacts on CT. }\end{array}$ \\
\hline 10. Technical errors: & $\begin{array}{l}\text {-Images sent to the wrong patient's folder. } \\
\text {-Report approved with ID of another radiologist } \\
\text {-Addendum added by error } \\
\text {-Failures due to machine resolution } \\
\text {-Voice recognition software error }\end{array}$ & \multicolumn{2}{|l}{} \\
\hline
\end{tabular}

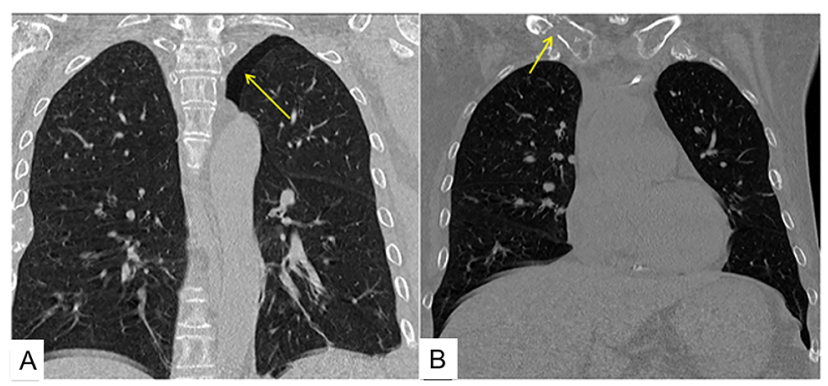

Fig. 3 (A and B) Under reading. Left-sided pneumothorax was reported on chest computed tomography (CT) (A) but the right clavicle fracture was not mentioned (B). Eventually, the patient was diagnosed to have myeloma with pathological fractures. An addendum was added to the CT report. This highlights the importance of following a checklist for reporting.

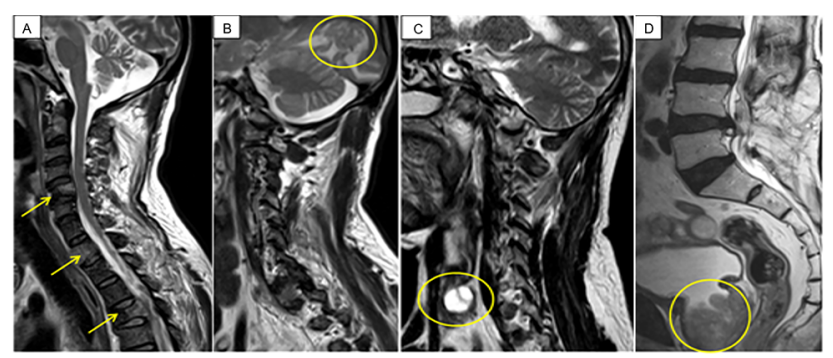

Fig. 4 (A-D) Location outside the field of interest. Multiple metastatic vertebral lesions in magnetic resonance imaging (MRI) spine (A) noted, but the brain metastasis (B) was not mentioned due to location in the top edge of the images. Similarly, thyroid nodules (C) and prostate tumor (D) were missed in different patients during spine reporting due to location out of the field of interest.

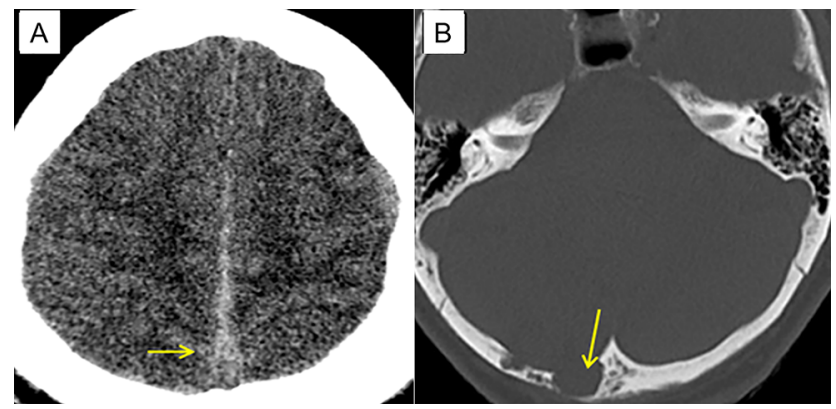

Fig. 6 (A and B) Over reporting. The normal mild hyperdensity of superior sagittal sinus on noncontrast computed tomography (CT) (A) and impressions on skull bone by arachnoid granulations (B) were reported as venous thrombosis and suspicious lytic skull lesions in 2 different patients respectively. The radiologist realized them later, and added an addendum, accepting the error in judgment.

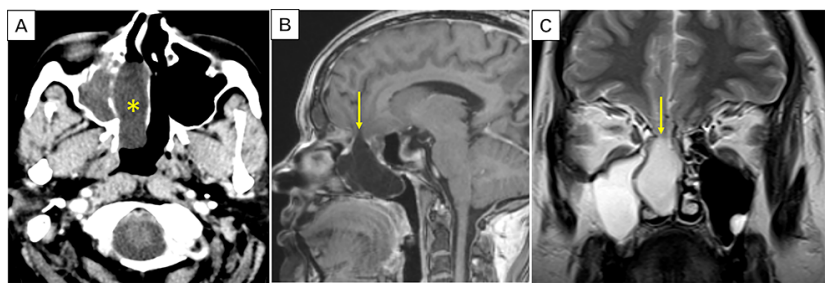

Fig. 8 (A-C) Limitations of modality. Computed tomography (CT) brain performed for headache showed no intracranial abnormality. Incidental hypodense content within the right maxillary sinus and the nasal cavity was suspected as a polyp. Because there was a bony defect in the anterior skull base, magnetic resonance imaging (MRI) was advised. Subsequently, after looking at the MRI findings (B and $\mathbf{C}$ ), the final diagnosis of meningocele was made. 

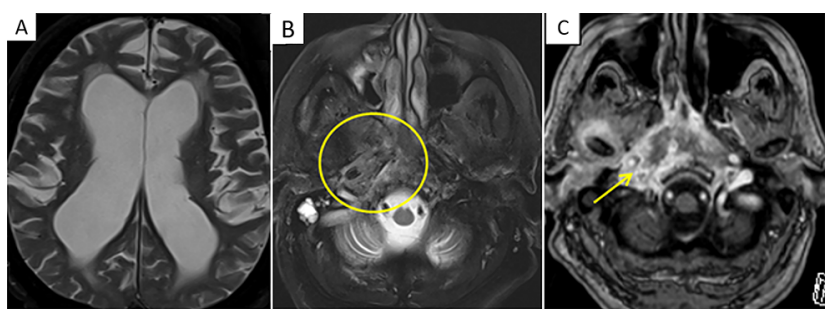

Fig. 5 (A and B) Under reading. Normal-pressure hydrocephalus was correctly reported in magnetic resonance imaging (MRI) brain (A), but the inflammatory changes in the single lower section of the skull base (circle) were not mentioned in the report. After 1 week, the patient presented with fever and cranial nerve palsies. This time, contrast MRI picked up the skull base osteomyelitis. (B) The missed findings were documented as a supplementary text in the old report.
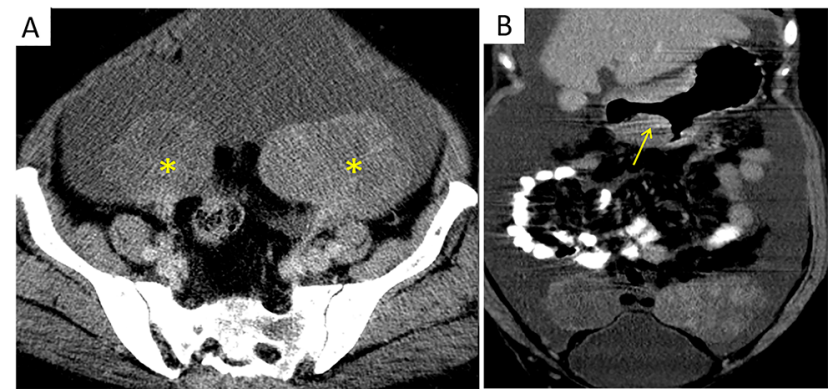

Fig. 7 (A and B) Over reliance on clinical history. The clinical history said "A 50-year-old lady with suspected ovarian malignancy and family of the same." The radiologist was biased by the statement and interpreted the computed tomography (CT) abdomen as "bilateral ovarian masses $(\mathbf{A})$, consistent with primary ovarian malignancy." On a second look at a later date, he discovered the stomach wall thickening (B). This later turned out to be gastric adenocarcinoma with Krukenberg ovarian deposits.

findings with older imaging brought at a later date. Out of the total of 97,003 reports, 35,891 were generated during emergency hours (6 p.m. to 8 a.m.) and addenda were added to $0.69 \%(n=250)$ of them. $1.35 \%(n=826 / 61,112)$ of the addenda was issued in the reports created during routine working hours.

\section{Clinical Significance}

Minor or no clinical impact was noted due to modifications in $82.3 \%$ of reports, whereas $17.6 \%$ of reports were of major clinical significance ( $\boldsymbol{- T a b l e ~} 2$ ). All the critical changes were made in less than one day and directly notified to the referring clinician. On subsequent review of patients' medical records, none of the critical addenda resulted in major adverse outcomes.

\section{Experience}

The addendum rate for radiologists with more than 6 years of experience was $1.5 \%$ ( $n=456 / 29,698)$, followed by $0.91 \%$ $(n=443 / 48,666)$ and $0.94 \%(n=177 / 18,639)$ for radiologists with 4 to 6 years and less than 4 -year experience, respectively.

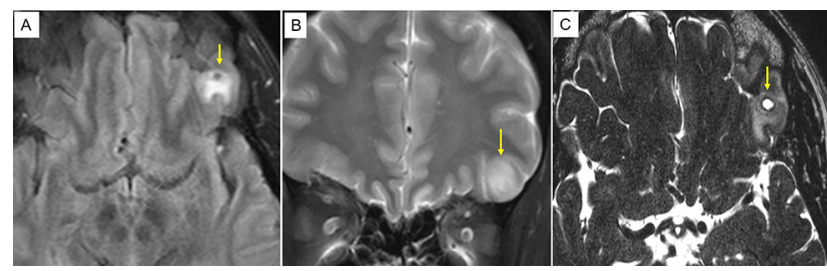

Fig. 9 (A-C) Limitations of sequences. Focal edema in the left basifrontal lobe detected on routine magnetic resonance imaging (MRI) (fluid-attenuated inversion recovery [FLAIR] and T2W) sequences. (A and $\mathbf{B}$ ) At this point, the radiologist could not single out one diagnosis but thought of neurocysticercosis. The report was approved with a request for an additional DRIVE sequence. The presence of cyst with surrounding edema (C) on DRIVE confirmed neurocysticercosis.

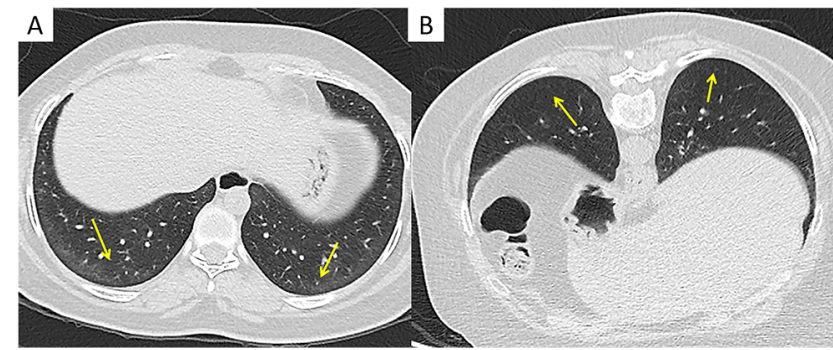

Fig. 10 (A and B) Limitations of technique. Basal ground-glass densities on computed tomography (CT) (A) were reported as "equivocal for early interstitial lung disease (ILD) or nonspecific dependent atelectasis. The patient was called back for prone sections and resolution of densities led to the exclusion of ILD (B). The change in the final impression was documented as an addendum.

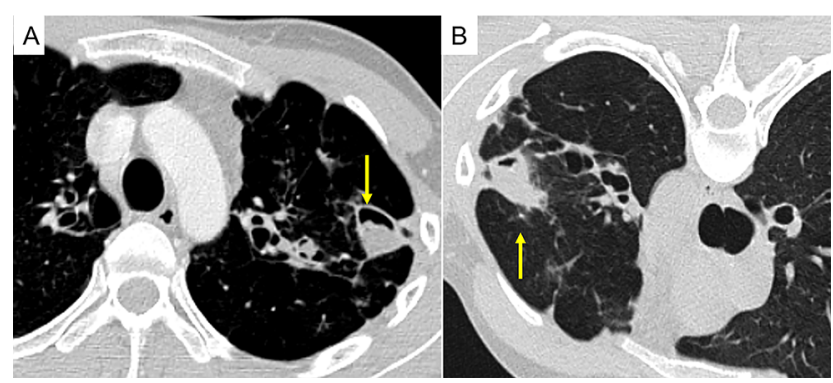

Fig. 11 Limitations of technique. Supine computed tomography (CT) thorax showed a cavity with soft tissue content within. Fungal ball was thought of and prone sections advised, which confirmed the diagnosis. The confirmation was added to the report as an addendum after the additional imaging.

\section{Discussion}

\section{Radiologic Errors}

To err is human; nevertheless, reporting errors is a complex issue and often not admitted or recorded due to fear of bad reputation and medical lawsuits. ${ }^{2,5}$ Radiologists are judged by their clinical colleagues by their "misses," and these misses are the major contributor to legal grievances among radiologists. ${ }^{6,7}$

Radiologists, referring doctors, and patients should be made aware of the fact that discrepancies in radiology reports 
Table 2 Classification of report addenda based on the magnitude of clinical impact

\begin{tabular}{|c|c|c|c|c|c|}
\hline Significance & & Grade & Description & Examples & $\begin{array}{l}\text { Frequency } \\
(n / 1,076)\end{array}$ \\
\hline \multirow{3}{*}{$\begin{array}{l}\text { Clinically } \\
\text { insignificant } \\
82 \%(n=886 / 1,076)\end{array}$} & 1 & $\begin{array}{l}\text { Negligible } \\
\text { change }\end{array}$ & $\begin{array}{l}\text { Adding information already } \\
\text { known to the referring doctor }\end{array}$ & $\begin{array}{l}\text { Gender discrepancy, mentioning the } \\
\text { type of surgery or site of biopsy }\end{array}$ & 702 \\
\hline & 2 & $\begin{array}{l}\text { Minor } \\
\text { change }\end{array}$ & $\begin{array}{l}\text {-No effect on investigations or } \\
\text { treatment } \\
\text {-Incidental findings not requir- } \\
\text { ing further studies }\end{array}$ & $\begin{array}{l}\text {-Incidental renal cysts } \\
\text {-Elaboration of disease description }\end{array}$ & 160 \\
\hline & 3 & $\begin{array}{l}\text { Moderate } \\
\text { change }\end{array}$ & $\begin{array}{l}\text { No effect on primary diagno- } \\
\text { sis or treatment, but requires } \\
\text { further investigations and } \\
\text { additional treatment }\end{array}$ & $\begin{array}{l}\text { Additional imaging for incidental } \\
\text { liver lesion, e.g., to confirm liver } \\
\text { hemangioma, adrenal adenoma }\end{array}$ & 24 \\
\hline \multirow{2}{*}{$\begin{array}{l}\text { Clinically } \\
\text { significant } \\
17.6 \%(n=190 / 1,076)\end{array}$} & 4 & $\begin{array}{l}\text { Major } \\
\text { change }\end{array}$ & $\begin{array}{l}\text { Changes the working diagnosis } \\
\text { or treatment }\end{array}$ & $\begin{array}{l}\text { Missing metastasis in known } \\
\text { malignancies }\end{array}$ & 185 \\
\hline & 5 & $\begin{array}{l}\text { Critical } \\
\text { change }\end{array}$ & $\begin{array}{l}\text {-Needs immediate treatment } \\
\text { modification or discontinuation }\end{array}$ & $\begin{array}{l}\text {-Missing hepatic abscesses that } \\
\text { require immediate drainage } \\
\text {-Missing acute infarcts, carotid } \\
\text { dissection }\end{array}$ & 5 \\
\hline
\end{tabular}

Table 3 Frequency of reasons for addenda generation (number and percentage)

\begin{tabular}{|l|l|}
\hline Reason for addenda insertion & Number (percentage) \\
\hline 1. Observational errors & $224(20.8 \%)$ \\
\hline -Under reading & 118 \\
\hline -All images not read/reported & 37 \\
\hline -Location & 56 \\
\hline -Prior examination & 13 \\
\hline 2. Interpretation errors & $191(17.7 \%)$ \\
\hline -Faulty reasoning & 52 \\
\hline -Limited differentials & 20 \\
\hline -Incomplete description & 110 \\
\hline -Over reporting & 9 \\
\hline 3. Communication errors & $316(29.3 \%)$ \\
\hline -Physician communication & 13 \\
\hline -Further recommendations & 38 \\
\hline -Typographic error & 136 \\
\hline -Erroneous template & 68 \\
\hline - Incomplete report & 61 \\
\hline 4. Study limitations & $155(14.4 \%)$ \\
\hline -Limitations of modality & 100 \\
\hline -Limited sequences/views & 30 \\
\hline -Limitations of technique & 25 \\
\hline 5. Clinical history & $36(3.3 \%)$ \\
\hline 6. Additional remarks & $39(3.6 \%)$ \\
\hline 7. Comparison & $27(2.5 \%)$ \\
\hline 8. Follow-up & $38(3.5 \%)$ \\
\hline 9. Patient related limitations & $26(2.4 \%)$ \\
\hline 10. Technical faults & $24(2.2 \%)$ \\
\hline
\end{tabular}

are well-recognized, sometimes inevitable and do not always equate to negligence. ${ }^{7}$ Instead of hiding them, we should see them as learning opportunities and initiate preventive strategies to reduce their occurrence. An essential step in this direction is to understand the sources of these errors.

\section{Prevalence of Radiologic Error: What is Already Known} Several studies in the past have used different methods and study populations to analyze radiological error rates and have obtained variable results ( - Table 4)..$^{1,8-16}$ This is because of the absence of a single, standard, and universally reproducible process of analyzing radiological errors.

The peer-review method is the most widely used, wherein a second radiologist reviews prior imaging and decides the degree of interobserver disagreements. ${ }^{17}$ This method is time-consuming and heavily dependent on the reviewer's

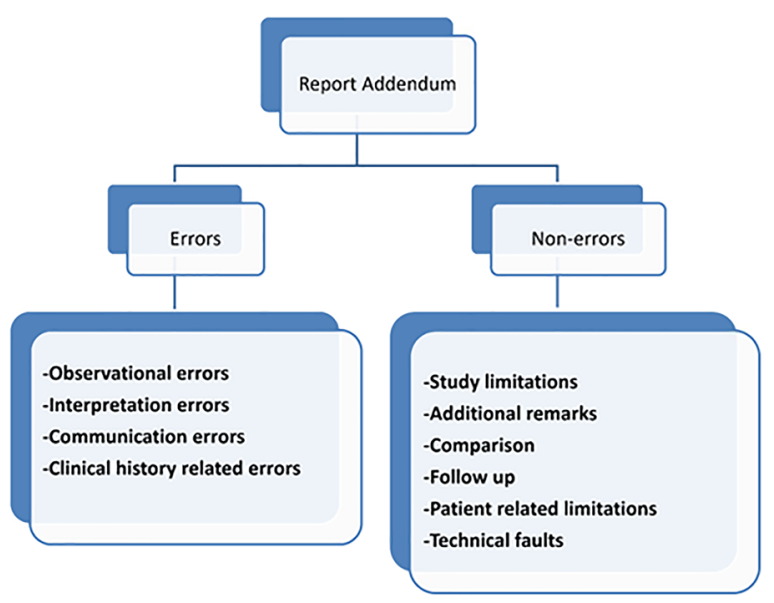

Fig. 12 Broad classification of addenda as error or non-error types. 


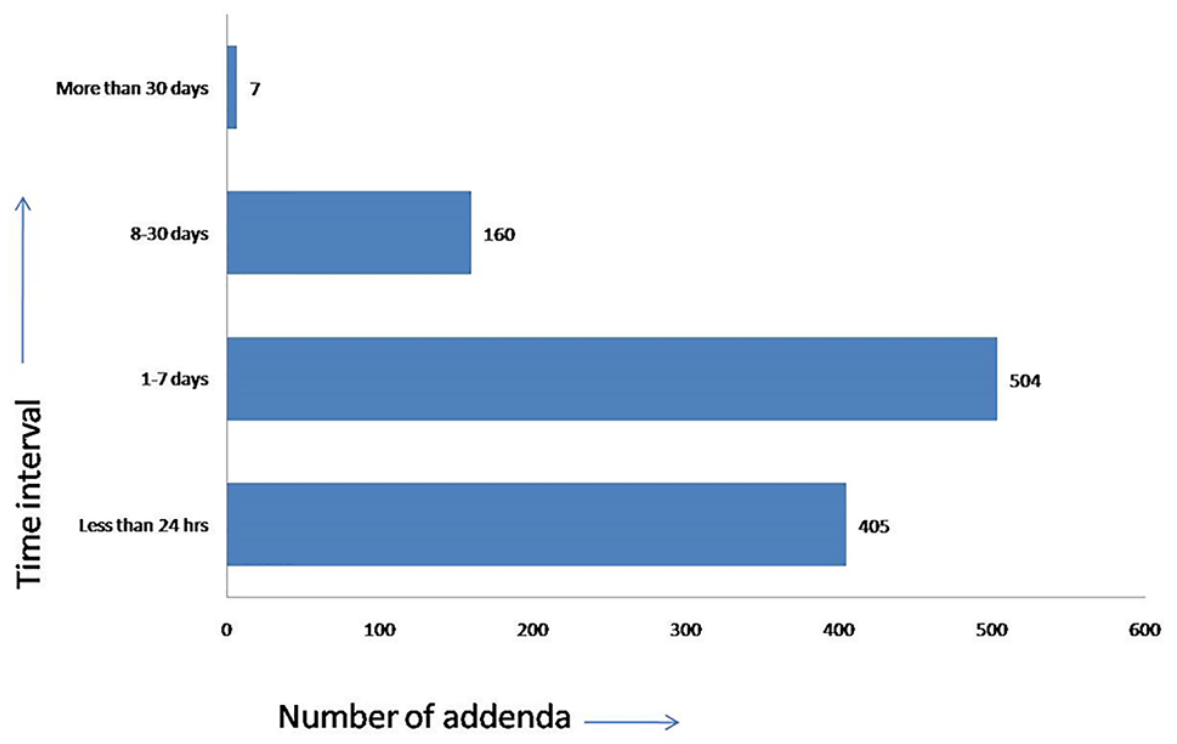

Fig. 13 Time delay between the original report and addenda generation.

opinion. Studies have compared discrepancy rates between experienced radiologists ${ }^{11,15,18}$; resident versus consultant radiologist ${ }^{12,13,19}$; preliminary versus final reports ${ }^{4}$; specialist versus general radiologists; ${ }^{14}$ etc. Borgstede et $\mathrm{al}^{20}$ and Soffa et $\mathrm{a}^{15}$ focused only on major disagreements and errors with potential clinical significance. Overall, these studies showed a wide range of discrepancy rates from 0.3 to $40 \%$.

There is limited literature that evaluates report addenda as a tool for error analysis, summarized in - Table 4. ${ }^{1,8-10}$ One such noteworthy work by Brigham et $\mathrm{al}^{8}$ used report addenda to calculate error rates in 5,568 reports and classified them based on etiology and image modality. These studies reflect an agreement that addenda analysis as a self-acknowledged method of error detection is less time consuming and minimizes the interobserver variability in image interpretation compared with the peer review method in previous works.

Several error classifications have been proposed in the past. The most notable works are by Renfrew et al in $1992^{21}$ and Kim and Mansfield ${ }^{22}$ in 2014. Majority of errors in both these classifications were contributed by under reading or observational errors. Our classification system is adopted from the previously published literature $\mathrm{e}^{8,21,22}$ and elaborated taking into consideration the reasons for addenda generation in our reports and errors prevalent at our institution. For example, we removed the broad category of "satisfaction of search" as due to the retrospective nature of the study, it was not possible to assess the thought process of the radiologist from the report. ${ }^{21}$ Few additions were made to the classification such as "comparison with the prior report" and "technical errors" which made a fair contribution to our data.

\section{Addenda: A Useful Tool to Study Errors}

Report addenda is a relatively new concept, with limited available literature exploring its role in error analysis. The purpose of studying the reasons for addenda generation is to get an idea about the areas where mistakes are made so that measures can be taken to reduce their occurrence by incorporating common misses into reporting checklists and radiology training.

We have the largest PACS in the country catering to a 3,000-bedded hospital, with an inbuilt facility to insert "addenda" to reports. Monthly audit of report addenda is one of the key performance indicators (KPI) that we assess for the National Accreditation Board for Hospitals and Healthcare Providers (NABH) accreditation purposes. An automatic computer-generated list of addenda from RIS is audited by a dedicated radiologist and the reasons and trends of report addenda and errors are studied. Through this retrospective study, we aimed to convey the lessons we learned through this exercise.

Our error rate is lower compared with most of the previously reported error rates between 3 to $40 \%{ }^{8,10,16,23}$ Majority of our errors were related to poor communication. These can not only cause ill-effects on patient management but also can create confusion in the minds of the reader. For example, writing "distal" urethral stricture instead of "proximal" or "arterial" thrombosis instead of venous completely changes the meaning of the report and can have significant repercussions on patient management. Some radiologists are dependent upon transcriptionists, who are in habit of copy/paste from common reporting templates, and finalizing such reports without reading introduces gender and age errors like writing "prostate" in female and "uterus" in males. ${ }^{24}$ These typographical errors reflect lack of focus, inattention to details, and, most importantly, not reviewing the typed or dictated report before approval.

Observational errors were the second most common type of errors, unlike other series that have reported this to be the most common error. ${ }^{3,22,25}$ Reducing the frequency of missing findings is a challenge for the radiologists. These errors occur due to failure to pay attention to all images and all areas within each image, which is likely to be influenced by 
Table 4 Compiled data of published studies on radiological errors

\begin{tabular}{|c|c|c|c|c|}
\hline Year & Author & $\begin{array}{l}\text { Nature of study } \\
\text { population }\end{array}$ & Aim & Comments \\
\hline 2017 & Balthazar et al ${ }^{9}$ & 418 addended reports & $\begin{array}{l}\text { Studied impact of trainee } \\
\text { (resident or fellow) involve- } \\
\text { ment on addendum rates }\end{array}$ & $\begin{array}{l}0.3 \% \text { addenda rate. Addendum in nontrainee reports } \\
12 \text { times more compared with trainee reports. Higher } \\
\text { likelihood of addendum in emergency or outpatient } \\
\text { than inpatient reports }\end{array}$ \\
\hline 2015 & Brigham et $a^{8}$ & $\begin{array}{l}5,568 \text { addended } \\
\text { reports across all the } \\
\text { imaging modalities }\end{array}$ & $\begin{array}{l}\text { Addenda classified based on } \\
\text { reason for generation and } \\
\text { imaging modality }\end{array}$ & $\begin{array}{l}0.8 \% \text { error rate. Poor communication }(44 \%) \text { and under- } \\
\text { reading }(7 \%) \text { most common. Most errors in positron } \\
\text { emission tomography (PET) }(19.45 / 1,000) \text {, followed } \\
\text { by magnetic resonance imaging (MRI) }(13.86 / 1,000)\end{array}$ \\
\hline 2015 & Baccei et al ${ }^{1}$ & $\begin{array}{l}305 \text { addended reports, } \\
\text { excluding mammo- } \\
\text { gram, breast MRI, and } \\
\text { satellite center reports }\end{array}$ & $\begin{array}{l}\text { Evaluated the impact of } \\
\text { provisional signing option } \\
\text { on addenda generation. } \\
\text { Classified addenda based } \\
\text { on time period and clinical } \\
\text { significance }\end{array}$ & $\begin{array}{l}\text { Provisional reporting reduced the overall number of } \\
\text { addenda ( } 0.44 \% \text { from } 0.92 \%) \text {, but increased rates of } \\
\text { clinically significant addenda from } 8.5 \text { to } 25.2 \%\end{array}$ \\
\hline 2011 & Hussain et al ${ }^{10}$ & $\begin{array}{l}\text { 62,500 reports with } \\
\text { addenda }\end{array}$ & $\begin{array}{l}\text { Classified addend based on } \\
\text { significance and time lag }\end{array}$ & $\begin{array}{l}1.7 \% \text { rate of addenda with } 8.5 \% \text { clinically significant } \\
\text { errors. } 82 \% \text { dictated within } 24 \text { hours of finalized } \\
\text { original reports }\end{array}$ \\
\hline 2010 & Abujudeh et al ${ }^{11}$ & $\begin{array}{l}90 \text { abdomen and pelvic } \\
\text { computed tomogra- } \\
\text { phy }(C T) \text { reported by } \\
\text { specialists }\end{array}$ & $\begin{array}{l}\text { Scans reinterpreted by same } \\
\text { radiologists to assess intra } \\
\text { and intrareader discrepancy } \\
\text { rates }\end{array}$ & $\begin{array}{l}\text { Focused on major discrepancy rate between } 26 \text { and } \\
32 \%\end{array}$ \\
\hline 2010 & Briggs et al ${ }^{12}$ & $\begin{array}{l}130 \text { polytrauma } C T \\
\text { initially reported } \\
\text { by on-call registrar } \\
\text { radiologists }\end{array}$ & $\begin{array}{l}\text { Compared discrepancy } \\
\text { rate between registrar and } \\
\text { consultant reports }\end{array}$ & $\begin{array}{l}\text { 25\% reports showed discrepancies between provi- } \\
\text { sional and final reports. } 4 \% \text { had significant misses }\end{array}$ \\
\hline 2007 & Ruchman et $\mathrm{al}^{13}$ & $\begin{array}{l}11,908 \text { emergency pre- } \\
\text { liminary reports inter- } \\
\text { preted by residents }\end{array}$ & $\begin{array}{l}\text { Studied discrepancy } \\
\text { between resident and } \\
\text { attending radiologist's final } \\
\text { interpretation }\end{array}$ & $\begin{array}{l}\text { Discrepancy rate was } 2.6 \% \text {. Preliminary interpretations } \\
\text { made by radiology residents were found reliable }\end{array}$ \\
\hline 2008 & Briggs et al ${ }^{14}$ & $506 \mathrm{CT}$ and MR of brain & $\begin{array}{l}\text { Compared the disagreement } \\
\text { rate between neuroradi- } \\
\text { ologists' second opinion } \\
\text { and initial interpretation by } \\
\text { general radiologists }\end{array}$ & $\begin{array}{l}13 \% \text { major and } 21 \% \text { minor discrepancy rates between } \\
\text { neuroradiologists and general radiologists }\end{array}$ \\
\hline 2004 & Soffa et al ${ }^{15}$ & $\begin{array}{l}\text { 6,703 reports, exclud- } \\
\text { ing CT and MRI }\end{array}$ & $\begin{array}{l}\text { Calculated disagreement } \\
\text { rates based on double } \\
\text { reading }\end{array}$ & $\begin{array}{l}\text { Overall disagreement rate of } 3.48 \% \text {. Disagreement } \\
\text { rate of } 3.03 \% \text { for general radiology, } 3.61 \% \text { for diagnos- } \\
\text { tic mammography, } 5.79 \% \text { for screening mammogra- } \\
\text { phy, and } 4.07 \% \text { for ultrasound }\end{array}$ \\
\hline 1999 & Gollub et al ${ }^{16}$ & $\begin{array}{l}203 \text { CTs of patients } \\
\text { with known } \\
\text { malignancies }\end{array}$ & $\begin{array}{l}\text { CTs reinterpreted inde- } \\
\text { pendently by two } \\
\text { radiologists }\end{array}$ & $\begin{array}{l}\text { Major and minor disagreement rate } 17 \text { and 20\%, } \\
\text { respectively. Actual change in treatment in 3\% reports }\end{array}$ \\
\hline
\end{tabular}

psychophysiological factors such as the satisfaction of search, level of alertness, work fatigue. ${ }^{6,12}$ They could also be affected by external factors such as reporting conditions, duration of reporting, distractions, the pressure to issue reports fast, nonavailability of relevant clinical data, suboptimal imaging, and conspicuity of findings. ${ }^{18,26}$

Though report addenda were most commonly inserted to correct the errors, in $28.7 \%$ cases, they were used to highlight new information that potentially have a role in the management of the patient. For example, comparisons with older studies done elsewhere made available at a later date, communicating the findings of an additional modality, correcting the scan date, adding a missed step in an intervention procedure, etc., may not critically affect the immediate management but are a part of the report. Hence, though the addenda rate in our reports was $1.1 \%$, the actual error rate was only $0.8 \%$ because of the dilution of our study sample by non-error addenda. In other words, addenda rate can overestimate error rates, when used to add specific information of low clinical relevance instead of crucial misses.

Addenda can also underestimate the actual error rate, as many errors go unrecorded and never come to the radiologist's attention unless pointed out by clinicians in multidisciplinary meetings or by colleagues in retrospect while reporting the follow-up scans.

Reasons for a higher percentage of addenda in reports by more experienced radiologists are possibly due to (1) higher proportion of cases finalized by them compared with the trainee residents, (2) referring clinicians directly discussing cases with senior radiologists making additional clinical data available to them resulting in necessary changes to the reports whenever required, and (3) the junior radiologists 
Table 5 Points to reduce radiological error and improve the quality of reports

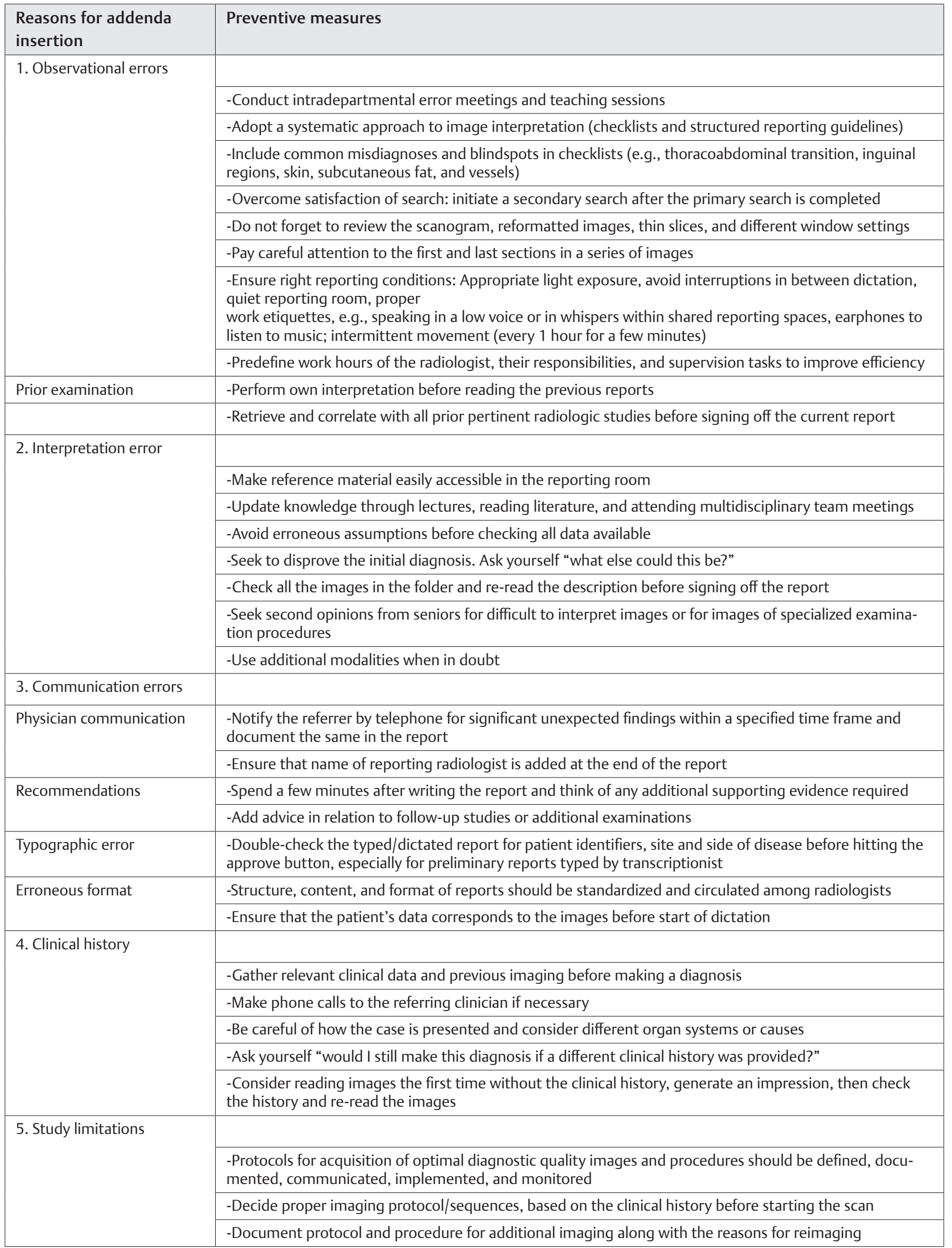


Table 5 (Continued)

\begin{tabular}{|l|l|}
\hline $\begin{array}{l}\text { Reasons for addenda } \\
\text { insertion }\end{array}$ & Preventive measures \\
\hline \multirow{3}{*}{. Others } & \\
\cline { 2 - 2 } & -Ensure timely and accurate generation and verification of reports by competent staff \\
\cline { 2 - 2 } & $\begin{array}{l}\text {-Gather and analyze feedback on content and quality of reports from referrer or colleagues about final } \\
\text { diagnosis to determine accuracy of reports }\end{array}$ \\
\cline { 2 - 2 } & $\begin{array}{l}\text {-Document any noncompliance with the guidelines through peer reviews and internal audits, along with } \\
\text { record of corrective steps taken } \\
\text {-When a report is found to be invalid after issuing, replace the original report by an addended report, } \\
\text { clearly identified as a replacement report }\end{array}$ \\
\hline
\end{tabular}

discussing their cases with the more experienced ones before finalizing reports, reducing their chances of errors.

The lower percentage of addenda in reports issued during the emergency hours can be attributed to (1) lesser distractions for the on-duty reporting radiologist while the pager is handled by a co-on call resident, and (2) direct phone conversation with the referring doctor giving a clearer picture about the patient's history and their clinical concerns.

\section{Communication of Addenda between Radiologists, Referring Physicians, and Patients}

Documentation of addenda does not conclude the responsibilities of the radiologist. It is also the radiologist's job to communicate the changed findings directly to the referring physician either face-to-face or by telephone on time and record the same in the modified report. This is the most crucial step to avoid potential mismanagement of patients. ${ }^{27}$

Radiologists are sometimes reluctant to document an addendum as they feel it is an admission of guilt and can lead to medical lawsuits, if not conveyed in a proper manner., ${ }^{5,28}$ Report addenda are accessible to the patients who perceive them as an open record of fallacies in reports, discovered in hindsight. This may leave an idea of gross medical malpractice in the minds of patients, even when it is not. ${ }^{29}$ In such situations, direct verbal communication of the changed or additional findings with an apology to the patients and the referring physician can prevent loss of trust.

\section{How to Reduce Errors?}

Based on the reasons for the creation of addenda in our reports, we propose some strategies to minimize radiological error, as enlisted in - Table 5. The key highlights are updating our skills through reading, discussion, and practice, being more vigilant at the time of reporting and creating a better reporting environment.

The NABH set up under the Quality Council of India has introduced a quality assurance program to monitor the quality of reports. The KPI include monitoring of the rate of variation of imaging findings compared with clinical diagnosis and histopathology, rate of radiology reporting errors, peer group reviews for radiology protocols, maintaining records of re-dos of radiology studies and audits on internal quality, critical reporting, and emergency radiology services. ${ }^{30}$ Sharing the lessons learned with radiology colleagues in the regular audits would minimize the need for addenda and improve the quality of reports. Some of these guidelines have been incorporated in - Table 5 .

Artificial intelligence methods can potentially increase the efficiency of radiologists and help to reduce some of the errors of omission/commission in the future. For example, Minn et al developed an error detection algorithm for detecting and notifying radiologists of gender and laterality errors. ${ }^{31}$ Tools such as computer-aided detection can assist the radiologists in disease detection, improve interpretation, and report generation. ${ }^{32}$

\section{Study Limitations}

The study is retrospective. There is a selection bias, as non-cross-sectional imaging modalities such as radiographs and mammograms were not included, due to subjective nature of interpretation and inter-/intraobserver variation of judgment in these studies. ${ }^{33}$ Provisional reports were also not included. In situations, where the type of error was found to be a combination/overlap of multiple categories, it was assigned to the single most appropriate group. The reported time of notification of addenda is not a precise representation of the actual time delay as some errors may have been notified to the referring physician much earlier than addition to the report.

\section{Conclusion}

Errors in radiology reports are rare but sometimes avoidable. Addenda gives a great platform to modify or correct reports at a later date, and we use this system as an opportunity to identify, quantify, and classify errors occurring in day-to-day radiology practice at a large tertiary care academic teaching hospital. Regular audits would minimize the need for addenda. This knowledge is immensely helpful in providing ideas to improve the quality of our reports and the patient's clinical records, ultimately benefiting the patient.

\section{Financial Support and Sponsorship \\ None.}

\section{Conflict of Interest}

There are no conflicts of interest. 


\section{Acknowledgments}

None.

\section{References}

1 Baccei SJ, Hoimes M, Shin H, Karam AR. Reducing radiology report addenda using provisionally signed status. J Am Coll Radiol 2015;12(1):108-110

2 Berlin L, Berlin JW. Malpractice and radiologists in Cook County, IL: trends in 20 years of litigation. AJR Am J Roentgenol 1995;165(4):781-788

3 Pinto A, Brunese L. Spectrum of diagnostic errors in radiology. World J Radiol 2010;2(10):377-383

4 Lauritzen PM, Andersen JG, Stokke MV, et al. Radiologist-initiated double reading of abdominal CT: retrospective analysis of the clinical importance of changes to radiology reports. BMJ Qual Saf 2016;25(8):595-603

5 Romano L, Pinto A, eds. Errors in Radiology. Milano: Springer Milan; 2012 2-5

6 Reiner BI. The challenges, opportunities, and imperative of structured reporting in medical imaging. J Digit Imaging 2009;22(6):562-568

7 Pinto A, Caranci F, Romano L, Carrafiello G, Fonio P, Brunese L. Learning from errors in radiology: a comprehensive review. Semin Ultrasound CT MR 2012;33(4):379-382

8 Brigham LR, Mansouri M, Abujudeh HH. Journal club: radiology report addenda: a self-report approach to error identification, quantification, and classification. AJR Am J Roentgenol 2015;205(6):1230-1239

9 Balthazar P, Konstantopoulos C, Wick CA, et al. Trainees may add value to patient care by decreasing addendum utilization in radiology reports. AJR Am J Roentgenol 2017;209(5):976-981

10 Hussain S, Allende MB, Karam AR, Hussain JS, Vijayaraghavan G. Addenda to the radiology report: what are we trying to convey? J Am Coll Radiol 2011;8(10):703-705

11 Abujudeh HH, Boland GW, Kaewlai R, et al. Abdominal and pelvic computed tomography (CT) interpretation: discrepancy rates among experienced radiologists. Eur Radiol 2010;20(8):1952-1957

12 Briggs $\mathrm{RH}$, Rowbotham E, Johnstone AL, Chalmers AG. Provisional reporting of polytrauma CT by on-call radiology registrars. Is it safe? Clin Radiol 2010;65(8):616-622

13 Ruchman RB, Jaeger J, Wiggins EF II, et al. Preliminary radiology resident interpretations versus final attending radiologist interpretations and the impact on patient care in a community hospital. AJR Am J Roentgenol 2007;189(3):523-526

14 Briggs GM, Flynn PA, Worthington M, Rennie I, McKinstry CS The role of specialist neuroradiology second opinion reporting: is there added value? Clin Radiol 2008;63(7):791-795

15 Soffa DJ, Lewis RS, Sunshine JH, Bhargavan M. Disagreement in interpretation: a method for the development of benchmarks for quality assurance in imaging. J Am Coll Radiol 2004;1(3):212-217

16 Gollub MJ, Panicek DM, Bach AM, Penalver A, Castellino RA Clinical importance of reinterpretation of body CT scans obtained elsewhere in patients referred for care at a tertiary cancer center. Radiology 1999;210(1):109-112

17 Strickland NH. Quality assurance in radiology: peer review and peer feedback. Clin Radiol 2015;70(11):1158-1164

18 Melvin C, Bodley R, Booth A, Meagher T, Record C, Savage P. Managing errors in radiology: a working model. Clin Radiol 2004;59(9):841-845

19 Chung JH, Strigel RM, Chew AR, Albrecht E, Gunn ML. Overnight resident interpretation of torso $\mathrm{CT}$ at a level 1 trauma center an analysis and review of the literature. Acad Radiol 2009;16(9):1155-1160

20 Borgstede JP, Lewis RS, Bhargavan M, Sunshine JH. RADPEER quality assurance program: a multifacility study of interpretive disagreement rates. J Am Coll Radiol 2004;1(1):59-65

21 Renfrew DL, Franken EA Jr, Berbaum KS, Weigelt FH, Abu-Yousef MM. Error in radiology: classification and lessons in 182 cases presented at a problem case conference. Radiology 1992;183(1):145-150

22 Kim YW, Mansfield LT. Fool me twice: delayed diagnoses in radiology with emphasis on perpetuated errors. AJR Am J Roentgenol 2014;202(3):465-470

23 Jackson VP, Cushing T, Abujudeh HH, et al. RADPEER scoring white paper. J Am Coll Radiol 2009;6(1):21-25

24 Mohan C. Quality program in radiology: persue or perish. Indian J Radiol Imaging 2017;27(1):1-3

25 DonaldJJ,BarnardSA.Common patterns in 558diagnosticradiology errors. J Med Imaging Radiat Oncol 2012;56(2):173-178

26 Brady AP. Error and discrepancy in radiology: inevitable or avoidable? Insights Imaging 2017;8(1):171-182

27 Wilcox JR. The written radiology report. Appl Radiol 2006; 35:33-37

28 Cleopas A, Villaveces A, Charvet A, Bovier PA, Kolly V, Perneger TV. Patient assessments of a hypothetical medical error: effects of health outcome, disclosure, and staff responsiveness. Qual Saf Health Care 2006;15(2):136-141

29 Maskell G. Error in radiology-where are we now? $\mathrm{Br}$ J Radiol 2019;92(1095):20180845

30 Zaidi Z. Accreditation standards for medical imaging services. Indian J Radiol Imaging 2010;20(2):89-91

31 Minn MJ, Zandieh AR, Filice RW. Improving radiology report quality by rapidly notifying radiologist of report errors. J Digit Imaging 2015;28(4):492-498

32 Shiraishi J, Li Q, Appelbaum D, Doi K. Computer-aided diagnosis and artificial intelligence in clinical imaging. Semin Nucl Med 2011;41(6):449-462

33 Robinson PJ, Wilson D, Coral A, Murphy A, Verow P. Variation between experienced observers in the interpretation of accident and emergency radiographs. $\mathrm{Br}$ J Radiol 1999;72(856):323-330 